\title{
EFFECT OF ARTEMISIA SPLENDENS POWDER AND EXTRACT ON BROILER CHICKEN'S PERFORMANCE, LYMPHOID ORGAN WEIGHT, GUT MORPHOLOGY AND SERUM BIOCHEMICALS DURING COCCIDIOSIS CHALLENGE.
}

L. N. Abdullah

Researcher
L. T. O. Al-Barwary

Assist. Prof.

Veterinary college, University of Duhok, Iraq

lilav.najm@yahoo.com

\begin{abstract}
The objective of this study was to investigate the efficacy of Artemisia splendens on performance, some serum biochemicals content, lymphoid organs and gut health of broiler chickens challenged with coccidia. This study was conducted at university of Duhok, college of agriculture. A total of 200 day-old Ross 308 chicks were assigned in to 5 treatments (4 replicates pens of $10 \mathrm{birds} /$ pen): unchallenged control (negative control); challenged control (positive control); challenged supplemented with salinomycin in feed (anticoccidial); challenged supplemented with Artemisia splendens in drinking water (AS1) and challenged supplemented with Artemisia splendens in feed (AS2). On day 9, challenged birds were inoculated with 5000 sporulated oocysts of Eimeria. The results showed that on day 24, challenged birds in negative control, anticoccidial AS1 and AS2 had higher weight gain and feed conversion ratio compared to positive control. No significant differences were detected between Birds in AS1, AS2 Anticoccidial and negative control for body weight gain and feed conversion ratio. On day 35, birds in AS1 as negative control and anticoccidial groups had higher $(\mathbf{P}<0.01)$ body weight gain and feed conversion ration compared to positive control. Negative control, anticoccidial, AS1 and AS2 birds significantly increased villous height and villous height/crypt depth and decreased crept depth when compared to positive control at day 24. The serum globulin concentration of AS1 birds was significantly higher than birds in negative control, positive control and anticoccidial. In conclusion, these results demonstrated the protective effects of Artemisia splendens against performance during coccidiosis challenge.
\end{abstract}

Key words: broiler chickens, performance, gut morphology, coccidiosis, Artemisia splendens

عبد الله و البرواري

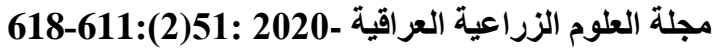
تأثير مسحوق و مسستخلص عشبة الثيح على أداء الانتاجي ,وزن الاعضاء الليمفاوي , الصفات النسيجية لامعاء والكيمياء

$$
\begin{aligned}
& \text { الحيوية في مصل فروج اللحم المعرضة للكوكسيديا. } \\
& \text { ليلاف نجم عبدالله لوقمان طيب عمر البرواري } \\
& \text { الاستاذ المساعد } \\
& \text { الباحثة }
\end{aligned}
$$

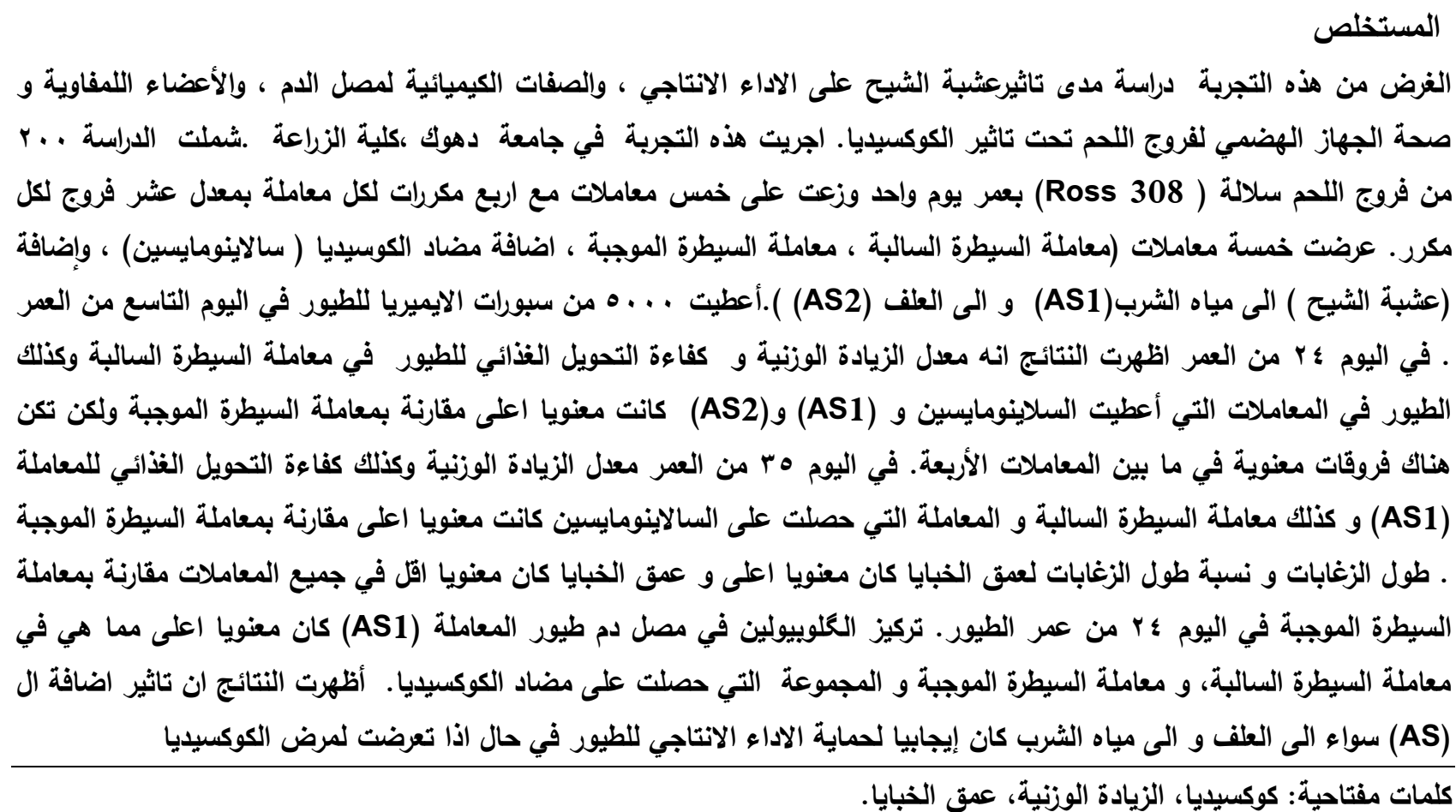

*Received:11/7/2019, Accepted:24/10/2019. 


\section{INTRODUCTION}

Poultry production has been increased substantially increased compared to other animals since 1970 (24). As poultry performance improved including feed conversion ratio, growth rate, the bird's health care became more demand (18). The health status is interlinked with gut microbial balance and micro and macro structural integrity of gut.(19). Gastrointestinal tract health affects digestion, metabolism, absorption, disease resistance and immune response $(11,24)$. This makes it important to pay attention to gastrointestinal health, because any slight change is mostly accompanied by disruption of gut health and thus overall performance. In poultry industry, enteric diseases are one of the most imperative illnesses because of performance reduction, decrease weight gain, increase feed conversion ratio and mortality, which have high economical losses(21). Many pathogens including bacteria, parasites, viruses and other infectious and non-infectious agents are convicted as possible causes of gastrointestinal disturbance ( enteric diseases)(20). Several conditions have been associated to gastrointestinal problems for instance necrotic enteritis, wet droppings, diarrhea, intestinal colibacillosis, dysbacteriosis, malabsorption syndrome and coccidiosis (9). Coccidiosis (Eimeria spp.) in poultry has been well documented and it is major economic importance in poultry industry. Different Eimeria spp. have been reported and each species causes disease in separate part of gastrointestinal tract. The protozoan parasites such as Eimeria can interrupt gut integrity by causing intestinal leakage, malabsorption, interruption of nutrient digestion, increased intestinal passage time, villus atrophy, reduced weight gain, reduced feed and water intake, and increased susceptibility to other disease agents (23). Traditionally, coccidiosis has been controlled by using anticoccidial. However, public concern over the use of in -feed anticoccidial and emergence of anticoccidial resistance led to ban use of anticoccidial chemicals as feed additives (17). Thus, new methods for controlling coccidiosis must be explored. Recently, there is increasing interest in the development of new methods or strategies for controlling and preventing coccidiosis in poultry. Artemisia spp has been used as antidisease agent (3). The Artemisia genus is belongs to Compositae (Asteraceae) family with over 300 species spread worldwide (14). It has been reported that the wild Artemisia essential oil had antifeedant, antibacterial, antipyretic, cytostatic activities (12). Supplementation of Artemisia in infected chickens with were able to protect birds from Eimeria tenella $(1,2)$. Also, they found that the administration of Artemisia was effective in reducing oocyst output of $E$. tenella and $E$. acervuline. The present study aimed to determine the efficacy of Artemisia splendens in reducing the severity of coccidiosis in broiler chickens experimentally infected with coccidiosis.

\section{MATERIAL AND METHODS Animal husbandry}

A total of 200 d-old Ross 308 chicks were obtained at hatching from the Qendil hatchery in Erbil, Kurdistan region of Iraq. Birds were allocated to 20 floor pens with 5 dietary treatments and with 4 replicates of 10 birds per treatment. Lighting program and daily temperature were adjusted according to the Ross 308 strain guideline. Water and feed were provided ad libitum. During the trial period, starter, grower and finisher diets were fed during d 0-10, d 10-24, and d 24-35 respectively. The primary determinants of performance, i.e., Mortality was recorded daily while cumulative pen weight and feed intake were recorded on d 10, d 24 and d 35 .

\section{Dietary treatments}

Three diets were formulated according to Ross 308 nutrient specifications as shown in (Table 1). Levels and trade-names of dietary additives were: negative control (no additive and no challenge ), Positive control (no additive and challenged), anticoccidial (control diet supplemented with anticoccidial $60 \mathrm{mg} / \mathrm{kg}$ salinomycine at starter, grower and finisher diets and challenged), Artemisia splendens 1 (AS1) $(0.4 \mathrm{~g} / 5 \mathrm{~L} \mathrm{AS}$ added in drinking water in starter, grower and finisher phases and challenged)., and Artemisia splendens 2 (AS2) (control diet supplemented with $4 \mathrm{~g} / \mathrm{kg}$ AS in starter, grower and finisher diets and challenged). Commercial Artemisia splendens was obtained from local shop in Duhok 
province. The extract prepared by adding 100 grams of Artemisia splendens to one litter of water. The Concept 5 feed formulation program (Creative Formulation Concepts, LLC, Annapolis, MD, USA) was used to formulate diets.

\section{Coccidia challenge}

The Eimeria used in this study was isolated in our laboratory from Animal production department farms of college of agriculture, university of Duhok. Fresh blood drops from infected birds were collected. The sample was transferred into $2 \mathrm{ml}$ microfuge tube then centrifuged at $6000 \mathrm{X} \mathrm{g}$ for 5 minutes and supernatant was discarded. The oocysts were allowed to sporulate in $2.5 \%(\mathrm{w} / \mathrm{v})$ potassium dichromate solution at $27{ }^{\circ} \mathrm{C}$ for three days. On day 9, challenged birds were inoculated with 5000 sporulated oocysts of Eimeria. Unchallenged birds received $1 \mathrm{~mL}$ of $1 \%$ (w/v) sterile saline.

\section{Sample collection}

On day 24, two birds were randomly selected from each pen weighed, and euthanized by cervical dislocation. Lymphoid organs weight including liver, heart, spleen, and bursa were taken. Digesta samples from the intestine were collected. Around $1 \mathrm{~g}$ of content was used to measure the $\mathrm{pH}$. Approximately $1 \mathrm{~cm}$ of the jejunum from one bird in each pen was collected for morphometric analysis. The intestinal samples were opened and gently flushed clean with phosphate buffered saline (PBS, pH 7.4) and then fixed in $10 \%$ buffered formalin.

\section{Measurements and Analysis Histology}

Fixed samples were dehydrated, cleared and embedded in paraffin wax for subsequent histological analysis. Consecutive longitudinal sections $(7 \mu \mathrm{m})$ were placed individually onto Superfrost ${ }^{\circledR}$ slides (Thermo Scientific, Rockville, MD, USA) and stained with hematoxylin and eosin. Villus height, muscle thickness, tip width, basal width, surface area and crypt depth were measured by the Dinoeye program and the images captured with a color video camera (Dino-eye 20). The height of 10 villi, depth of 10 crypts, width of 10 villi tips, width of 10 villi basal and thickness of 10 muscles were measured from each replicate. The means were obtained from villus height and crypt depth, the villus height/crypt depth ratio was determined.

\section{Serum biochemical}

At day 24 of age, blood samples were collected from the jugular vein and serum was separated for determination of total protein, albumin, cholesterol, alanine transaminase (ALT) and aspartate aminotransferase (AST). For individual serum sample determination, an automatic analyzer (TOKYO BOEKI MEDICAL SYSTEM).

\section{Statistical Analysis}

The SAS statistical package (PROC GLM) was used to determine significance of main effects (SAS, 2013). Duncan's multiple range test was used to detect the differences between individual treatment means. 
Table1. composition and calculation of experimental diets for the starter, grower and finisher rations

\begin{tabular}{|c|c|c|c|}
\hline Ingredients percentage & Starter & Grower & Finisher \\
\hline Corn & 53.06 & 56.9 & 61.74 \\
\hline Soybean meal (Argentina) & 31.48 & 32.89 & 28.23 \\
\hline Fish meal (Argentina) & 4 & - & - \\
\hline Vegetable oil & 3 & 4.48 & 4.57 \\
\hline Limestone & 2 & 1.39 & 1.35 \\
\hline Dical Phos & 2.27 & 0.95 & 1.35 \\
\hline Salt & 0.11 & 0.19 & 0.08 \\
\hline D,L-methionine & 0.38 & 0.32 & 0.24 \\
\hline L-lysine HCl & 0.5 & 0.26 & 0.21 \\
\hline L-threonine & 0.25 & 0.23 & 0.09 \\
\hline Broiler premix & 2.5 & 2.5 & 2.5 \\
\hline \multicolumn{4}{|l|}{ Calculated analysis } \\
\hline ME (kcal/kg) & 3000 & 3150 & 3200 \\
\hline Crude protein \% & 23 & 21 & 19.16 \\
\hline Crude fiber \% & 2.25 & 2.38 & 2.33 \\
\hline Digestible Arginine \% & 1.29 & 1.14 & 0.99 \\
\hline Digestible Lysine \% & 1.29 & 1.14 & 0.99 \\
\hline Digestible $\mathrm{M}+\mathrm{C} \%$ & 0.87 & 0.84 & 0.73 \\
\hline Digestible Tryptophan \% & 0.226 & 0.24 & 0.21 \\
\hline Digestible Isoleucine \% & 0.87 & 0.81 & 0.73 \\
\hline Digestible Threonine \% & 0.82 & 0.73 & 0.63 \\
\hline Digestible Valine \% & 0.99 & 0.92 & 0.83 \\
\hline Calcium \% & 1.60 & 0.9 & 0.85 \\
\hline Sodium \% & 0.16 & 0.160 & 0.16 \\
\hline Chloride \% & 0.35 & 0.312 & 0.23 \\
\hline Linoleic \% & 2.18 & 2.64 & 2.72 \\
\hline
\end{tabular}

\section{RESULTS AND DISCUSSION}

\section{Broiler performance}

Birds performance at day 10, 24 and 35 are showed in Table 2. At day 10, No significant differences were detected among treatments for body weight gain and feed conversion ratio. However, birds fed anticoccidial had higher $(\mathrm{P}<0.05)$ feed intake than birds fed AS 1 and AS2. From Day 0-24, the effect of the coccidia challenge was clearly visible (Table 2). Positive control birds had poorer $(\mathrm{P}<0.0001)$ feed conversion ratio and body weight gain and higher $(\mathrm{P}<0.004)$ feed intake compared to negative control, anticoccidial, AS1 and AS2. Birds feed anticoccidial had significantly higher body weight gain compared to negative control. Feed intake of nonchallenged birds was less than that of challenged control (positive control), anticoccidial, AS1 and AS2. Performance results from day 0-35, positive control had lower body weight gain $(\mathrm{P}<0.02)$ than negative control, anticoccidial and AS1. On the other hand, no significant different was found between positive control and AS2. Feed conversion ratio of positive control was significantly higher than other treatment groups. AS2 birds significantly increased feed conversion ratio compared to negative control and anticoccidial birds.

\section{Relative organ percentage}

Relative organs percentages from live body weight results at day 24 are present in Table 3. Although, no significant differences detected among treatment groups in spleen and bursa percentage from live body weight, birds fed AS1 and AS2 increased significantly gizzard and liver percentage in comparison to birds fed anticoccidial. Positive control birds had higher $(\mathrm{P}<0.015)$ percentage of gizzard when compared to anticoccidial group.

\section{Gut morphology}

The morphology of jejunum was measured at day 24. The challenged birds with no additives (positive control) had shorter jejunal villi $(\mathrm{P}<0.0001)$ compared to those in the negative control, anticoccidial, AS1 and AS2 group (Table 4). The villi heights of anticoccidial 
group were significantly longer than negative control group and AS2, but not different than AS1 group. Crypt depth of negative control, anticoccidial AS1and AS2 groups were reduced $(\mathrm{P}<0.0001)$ in comparison to positive control group. Significantly shorter crypt depth was recorded for negative control. The villus/crypt ratio of positive control birds was significantly lower overall treatments. No significant differences were observed for villus/ crypt ratio between negative control and AS1, but anticoccidial and AS2 groups had lower villus/crypt ratio when compared to negative control and AS1 groups. The muscle thickness results showed that anticoccidial birds had significantly higher muscle thickness compared with AS1, AS2 and negative control birds. The muscle thickness of birds fed AS1 and AS2 were not significantly different than negative control birds.

Serum biochemical parameters

The serum biochemical parameters including cholesterol, total protein, albumin globulin, alanine transaminase (ALT) and aspartate aminotransferase (AST) were measured at day 24. No significant differences were observed between treatments for cholesterol, albumin, ALT and AST. However, birds in SA1 and AS2 groups had higher $(\mathrm{P}<0.05)$ serum protein than birds in anticoccidial group. The serum globulin concentration of AS1 birds was significantly higher than birds in negative control, positive control and anticoccidial, while the globulin concentration was not different in AS1 and AS2 bird

Table 2. Effect of adding Artemisia splendens on bird's performance at day 10, 24 and 35 under coccidiosis challenge

\begin{tabular}{|c|c|c|c|c|c|c|c|}
\hline Age (day) & $\begin{array}{c}\text { Negative } \\
\text { control }\end{array}$ & $\begin{array}{c}\text { Positive } \\
\text { control }\end{array}$ & $\begin{array}{c}\text { Anticoccidi } \\
\text { al } \\
\end{array}$ & AS1 & AS2 & P-value & $\begin{array}{c}\text { Pooled } \\
\text { SEM }\end{array}$ \\
\hline \multicolumn{8}{|c|}{ body weight gain (g/bird) } \\
\hline 0-10 & 247 & 234 & 249 & 242 & 241 & 0.61 & 3.031 \\
\hline $0-24$ & $975^{b}$ & $882^{\mathrm{c}}$ & $1054^{\mathrm{a}}$ & $1004^{\mathrm{ab}}$ & $1002^{\mathrm{ab}}$ & 0.0001 & 15.60 \\
\hline $0-35$ & $1879^{a}$ & $1698^{c}$ & $1903^{a}$ & $1829^{a b}$ & $1775^{\text {bc }}$ & 0.02 & 20.97 \\
\hline \multicolumn{8}{|c|}{ Feed intake (g/bird) } \\
\hline $0-10$ & $294^{\text {ab }}$ & $293^{\text {ab }}$ & $296^{\mathrm{a}}$ & $285^{\mathrm{bc}}$ & $284^{\mathrm{c}}$ & 0.02 & 1.61 \\
\hline $0-24$ & $1369^{c}$ & $1467^{\mathrm{a}}$ & $1418^{b}$ & $1420^{b}$ & $1424^{b}$ & 0.004 & 9.15 \\
\hline $0-35$ & 2787 & 2859 & 2764 & 2753 & 2807 & 0.43 & 18.64 \\
\hline \multicolumn{8}{|c|}{ Feed conversion ratio $(F C R)$} \\
\hline 0-10 & 1.197 & 1.254 & 1.193 & 1.178 & 1.180 & 0.51 & 0.014 \\
\hline $0-24$ & $1.43^{b}$ & $1.569^{\mathrm{a}}$ & $1.345^{b}$ & $1.417^{b}$ & $1.410^{b}$ & 0.0001 & 0.027 \\
\hline $0-35$ & $1.483^{\mathrm{c}}$ & $1.686^{a}$ & $1.453^{\mathrm{c}}$ & $1.507^{b c}$ & $1.582^{b}$ & 0.0001 & 0.022 \\
\hline
\end{tabular}

a, b,c means in rows with different superscripts are significantly different $(P<0.05)$.

AS1=0.4g/5L Artemisia splendens added in drinking water in starter, grower and finisher phases,

AS2=control diet supplemented with $4 \mathrm{~g} / \mathrm{kg}$ Artemisia splendens in starter, grower and finisher diets

Table 3. Effect of adding Artemisia splendens on relative weights (\%) of some organs fed different treatment diets at $\mathbf{2 4}$ days of age under coccidiosis challenge.

\begin{tabular}{|c|c|c|c|c|c|c|c|}
\hline $\begin{array}{l}\text { Treatments } \\
\text { Parameters }\end{array}$ & $\begin{array}{c}\text { Negative } \\
\text { control }\end{array}$ & $\begin{array}{c}\text { Positive } \\
\text { control }\end{array}$ & Anticoccidial & AS1 & AS2 & P-value & $\begin{array}{c}\text { Pooled } \\
\text { SEM }\end{array}$ \\
\hline Liver \% & $3.108^{\mathrm{ab}}$ & $2.820^{a b}$ & $2.165^{b}$ & $3.894^{\mathrm{a}}$ & $3.378^{\mathrm{a}}$ & 0.03 & 0.188 \\
\hline Gizzard \% & $3.725^{\mathrm{ab}}$ & $3.959^{\mathrm{a}}$ & $2.659^{b}$ & $4.781^{\mathrm{a}}$ & $4.499^{a}$ & 0.015 & 0.230 \\
\hline Bursa \% & 0.148 & 0.210 & 0.158 & 0.132 & 0.092 & 0.071 & 0.013 \\
\hline Spleen \% & 0.103 & 0.104 & 0.072 & 0.098 & 0.075 & 0.21 & 0.006 \\
\hline
\end{tabular}

${ }^{a, b}$ means in rows with different superscripts are significantly different $(P<0.05)$.

$\%=$ organ percentage from

AS1=0.4g/5L Artemisia splendens added in drinking water in starter, grower and finisher phases

AS2=control diet supplemented with $4 \mathrm{~g} / \mathrm{kg}$ Artemisia splendens in starter, grower and finisher diets 
Table 4. Effect of adding Artemisia splendens on villus height, crypt depth, villi/crypt ratio and muscle thickness at 24 days of age under coccidiosis challenge

\begin{tabular}{|c|c|c|c|c|c|c|c|}
\hline $\begin{array}{l}\text { Treatments } \\
\text { Parameters }\end{array}$ & $\begin{array}{c}\text { Negative } \\
\text { control }\end{array}$ & $\begin{array}{l}\text { Positive } \\
\text { control }\end{array}$ & $\begin{array}{c}\text { Anticoccidi } \\
\text { al }\end{array}$ & AS1 & AS2 & P-value & $\begin{array}{c}\text { Pooled } \\
\text { SEM }\end{array}$ \\
\hline Villus height $\mu m$ & $974^{b}$ & $864^{\mathrm{c}}$ & $1107^{\mathrm{a}}$ & $1041^{\mathrm{ab}}$ & $\mathbf{9 7 3}^{\mathrm{b}}$ & 0.0001 & 11.31 \\
\hline Crypt depth $\mu m$ & $178^{d}$ & $351^{a}$ & $288^{b c}$ & $192^{\mathrm{dc}}$ & $222^{\mathrm{c}}$ & 0.0001 & 7.50 \\
\hline Villi/crypt ratio & $5.6^{\mathrm{a}}$ & $2.6^{c}$ & $4.1^{b}$ & $5.5^{\mathrm{a}}$ & $4.5^{b}$ & 0.0001 & 0.128 \\
\hline Muscle thickness $\mu m$ & $214^{\mathrm{bc}}$ & $235^{a b}$ & $281^{a}$ & $166^{\mathrm{c}}$ & $186^{\mathrm{c}}$ & 0.0001 & 7.40 \\
\hline
\end{tabular}

${ }^{a, b, c}$ means in rows with different superscripts are significantly different $(P<0.05)$.

AS1 $=0.4 \mathrm{~g} / 5 \mathrm{~L}$ Artemisia splendens added in drinking water in starter, grower and finisher phases

AS2=control diet supplemented with $4 \mathrm{~g} / \mathrm{kg}$ Artemisia splendens in starter, grower and finisher diets

Table 5. Effect of adding Artemisia splendens on on serum biochemical contents at 24 days of age under coccidiosis challenge

\begin{tabular}{|c|c|c|c|c|c|c|c|}
\hline $\begin{array}{l}\text { Treatments } \\
\text { Parameters }\end{array}$ & $\begin{array}{c}\text { Negative } \\
\text { control }\end{array}$ & $\begin{array}{l}\text { Positive } \\
\text { control }\end{array}$ & $\begin{array}{c}\text { Anticocci } \\
\text { dial }\end{array}$ & AS1 & AS2 & P-value & $\begin{array}{l}\text { Pooled } \\
\text { SEM }\end{array}$ \\
\hline Cholesterol(mg/dl) & 102 & 111 & 86 & 93 & 94 & 0.48 & 4.429 \\
\hline Total protein(g/dl) & $2.6^{\mathrm{ab}}$ & $2.53^{\mathrm{ab}}$ & $1.79^{b}$ & $3.04^{\mathrm{a}}$ & $2.89^{\mathrm{a}}$ & 0.053 & 0.151 \\
\hline $\operatorname{Albumin}(\mathrm{g} / \mathrm{dl})$ & 1.01 & 1.06 & 0.71 & 0.72 & 0.92 & 0.257 & 0.062 \\
\hline Globulin (g/dl) & $1.58^{\mathrm{bc}}$ & $1.48^{b c}$ & $1.09^{c}$ & $2.36^{\mathrm{a}}$ & $1.98^{a b}$ & 0.008 & 0.131 \\
\hline $\operatorname{ALT}(\mathbf{U} / \mathbf{L})$ & 2.95 & 4.55 & 2.3 & 2.75 & 2.45 & 0.199 & 0.331 \\
\hline $\operatorname{AST}(\mathbf{U} / \mathbf{L})$ & 183 & 196 & 133 & 177 & 160 & 0.249 & 9.33 \\
\hline
\end{tabular}

${ }^{a, b, c}$ means in rows with different superscripts are significantly different $(\mathbf{P}<0.05)$.

AS1 $=0.4 \mathrm{~g} / 5 \mathrm{~L}$ Artemisia splendens added in drinking water in starter, grower and finisher phases

AS2=control diet supplemented with $4 \mathrm{~g} / \mathrm{kg}$ Artemisia splendens in starter, grower and finisher diets

ALT = alanine transaminase, and AST = aspartate aminotransferase (AST).

Broiler chicken's performance is closely related to the growth, and health of the gastrointestinal tract. The gastrointestinal health plays a significant role in achieving optimum productivity. It affects feed digestion, absorption and metabolism, energy and protein utilization and disease resistance. Coccidiosis infection was successfully induced in this study as shown by depression of body weight gain, feed conversion ratio, feed intake, gut integrity and bloody diarrhea. The current study showed no significant differences between treatments for body weight gain and feed conversion ratio during starter phase. However, on day 24, AS1 and AS2 were as anticoccidial in protecting performance decline from coccidiosis and exhibit significantly better body weight gain and feed conversion than positive control. At day 35, AS1 and AS2 had lower feed conversion ratio $(\mathrm{P}<0.0001)$ and AS1 had higher body weight gain compared to positive control. This was the case of Brisibe (4) study when dried Artemisia protected performance decline during coccidiosis. Kheirabadi (13) postulated that the granulated extract of Artemisia improved performance at day 42 including body weight gain, feed intake and feed conversion ratio of broiler chickens inoculated with suspension of $2 \times 10^{5}$ oocysts of Eimeria tenella,Eimeria maxima,Eimeria acervulina and Eimeria necatrix. Drăgan (6) infected broiler chickens with Eimeria tenella (1500 oocysts/chicken) and treated with Artemisia annua as powder in feed. At day 32 post infection, they found Artemisia annua had the highest body weight gain and the bes feed conversion among the experimental groups. The improvement of performance of broiler chickens Artemisia in both feed and Artemisia extract during coccidiosis challenge, may be due to that the Artemisia had anticoccidial activity by reducing fecal oocyst output (7) and gastrointestinal tract lesion score from coccidiosis (2). The obtained results showed that the birds fed Artemisia splendens either as powder or extract significantly improve gut health integrity by increasing villous height and villous to crypt depth ratio and reducing crypt depth. All mentioned above may be the indication of improved gut health which resulting in better performance. This study also demonstrated that coccidia challenge cause dramatical changes in gastrointestinal morphology and blood serum biochemicals. After coccidia challenge at day 24, positive control (challenged control) had significantly shorter villous height, lower villous height to crypt ratio and higher crypt depth compared with un challenged control (negative control) 
and challenged birds received anticoccidial and Artemisia splendens. These results were in agreement with the finding of M'Sadeq (16) where a severely impaired jejunal morphology was observed in Eimeria challenged birds pathogen . the presence of pathogens in gastrointestinal tract are considered to enterocyte cells damage, which result in deeper crypts (16). Deeper crypts, would lead to a higher energy utilization for maintenance of digestive tract instead be used for growth and improved performance. Plant extract have received a great deal of attention because of their ability to manipulate gut micro-flora (10), antimicrobial properties (5), improve immune property(8), and also coccidiostat activity(2, 25). Also, birds fed Artemisia splendens extract had higher levels of serum globulin over negative control, positive control and anticoccidial birds. It is believed that the higher serum globulin concentration associated with strong innate immune response (22). The increase of serum globulin concentration in this study probably may be due to immunostimulants effect of Artemisia splendens. It has been reported that dietary supplementation of Artemisia in rabbits increased $(\mathrm{P}<0.05)$ duodenum and ileum $\operatorname{IgA}$, and significantly decreased IL2 and IL6 content in jejunum and ileum (15). This study was successful in representing the coccidiosis challenge model. Artemisia splendens was effective in controlling performance declined during coccidiosis challenge. Artemisia splendens was effective in improving gut integrity by increasing villous height and villous/crypt ratio. Also, Artemisia splendens acted as immunostimulants by increasing blood serum globulin concentration. These results indicate that Artemisia splendens can used as a tool to reduce severity of cocciciosis.

\section{REFERENCES}

1. Allen, $P$ C and R Fetterer. 2002.Recent advances in biology and immunobiology of Eimeria species and in diagnosis and control of infection with these coccidian parasites of poultry. Clinical Microbiology Reviews, 15(1): 58-65

2. Allen, P C, J Lydon, and H D Danforth. 1997.Effects of components of Artemisia annua on coccidia infections in chickens. Poultry Science, 76(8): 1156-1163
3.Arab, H, S Rahbari, A Rassouli, M Moslemi, and F Khosravirad. 2006.Determination of artemisinin in Artemisia sieberi and anticoccidial effects of the plant extract in broiler chickens. Tropical Animal Health and Production, 38(6): 497-503

4. Brisibe, E A, U E Umoren, P U Owai, and F Brisibe. 2008.Dietary inclusion of dried Artemisia annua leaves for management of coccidiosis and growth enhancement in chickens. African Journal of Biotechnology, 7(22): 4083-4092

5. Cowan, M M. 1999.Plant products as antimicrobial agents. Clinical Microbiology Reviews, 12(4): 564-582

6.Drăgan, L, A Titilincu, I Dan, I Dunca, M Drăgan, and V Mircean. 2010.Effects of Artemisia annua and Pimpinella anisum on Eimeria tenella (Phylum Apicomplexa) low infection in chickens. Science Parasitology 11(2): 77-82

7. Drăgan, L, A Titilincu, I Dan, I Dunca, M Drăgan, and V Mircean. 2010.Effects of Artemisia annua and Pimpinella anisum on Eimeria tenella (Phylum Apicomplexa) low infection in chickens. Science Parasitology, 11(2): 77-82

8. Guo, F, H Savelkoul, R Kwakkel, B Williams, and M Verstegen. 2003. Immunoactive, medicinal properties of mushroom and herb polysaccharides and their potential use in chicken diets. World's Poultry Science Journal, 59(4): 427-440

9. Hafez, H M. 2011.Enteric diseases of poultry with special attention to Clostridium perfringens. Pakistan Veterinary Journal, 31(2011): 175-184

10. Hashemi, S R and H Davoodi. 2011.Herbal plants and their derivatives as growth and health promoters in animal nutrition. Veterinary Research Communications, 35(3): 169-180

11. Kelly, D and S Conway. 2001.Genomics at work: the global gene response to enteric bacteria. Gut, 49(5): 612-613

12. Khattak, S G, S N Gilani, and M Ikram. 1985.Antipyretic studies on some indigenous Pakistani medicinal plants. Journal of Ethnopharmacology, 14(1): 45-51

13. Kheirabadi, K P, J K Katadj, S Bahadoran, J A T da Silva, A D Samani, and M C Bashi. 2014.Comparison of the anticoccidial effect of 
granulated extract of Artemisia sieberi with monensin in experimental coccidiosis in broiler chickens. Experimental Parasitology, 141: $129-133$

14. Kostadinović, L M, I S Čabarkapa, J D Lević, Š M Kormanjoš, S J Teodosin, and S A Sredanović. 2014.Effect of Artemisia absinthium essential oil on antioxidative systems of broiler's liver. Food and Feed Research, 41(1): 11-17

15. Liu, L, W Zuo, and F Li. 2019.Dietary addition of Artemisia argyi reduces diarrhea and modulates the gut immune function without affecting growth performances of rabbits after weaning. Journal of Animal Science, 97(4): 1693-1700

16. M'Sadeq, S A, S-B Wu, M Choct, R Forder, and R A Swick. 2015.Use of yeast cell wall extract as a tool to reduce the impact of necrotic enteritis in broilers. Poultry Science, 94(5): 898-905

17. M'Sadeq, S A, S-B Wu, R A Swick, and M Choct. 2015.Dietary acylated starch improves performance and gut health in necrotic enteritis challenged broilers. Poultry Science, 94(10): 2434-2444

18. M'Sadeq, S. 2019.Effect of dietary supplementation of miaclost on performance and gut morphology in broiler chickens challenged with Escherichia coli. Iraqi Journal of Agricultural Science 2(50
19. M'Sadeq, S A, S-B Wu, M Choct, and R A Swick. 2015.Heat production and energy efficiency of broilers infected with necrotic enteritis. Avian Diseases, 60(1): 50-55

20. Reynolds, D. 2003.Multi-causal enteric diseases. Diseases of Poultry, 11th ed. YM Saif, ed. Blackwell, Ames, IA: 1169-1170

21. Timbermont, L, F Haesebrouck, R Ducatelle, and F Van Immerseel. 2011.Necrotic enteritis in broilers: an updated review on the pathogenesis. Avian Pathology, 40(4): 341-347

22. Wiegertjes, $G$ F, $R$ M Stet, $H \quad K$ Parmentier, and $\mathrm{W} B$ van Muiswinkel. 1996.Immunogenetics of disease resistance in fish: a comparative approach. Developmental \& Comparative Immunology, 20(6): 365-381 23. Williams, R. 2005.Intercurrent coccidiosis and necrotic enteritis of chickens: rational, integrated disease management by maintenance of gut integrity. Avian Pathology, 34(3): $159-180$

24. Yegani, M and D Korver. 2008.Factors affecting intestinal health in poultry. Poultry Science, 87(10): 2052-2063

25. Youn, H J and J W Noh. 2001.Screening of the anticoccidial effects of herb extracts against Eimeria tenella. Veterinary Parasitology, 96(4): 257-263. 